\title{
La economía antioqueña antes de la Independencia, 1760-1821
}

\section{Economy in Antioquia before Independence, 1760-1821}

\author{
Juan Carlos Jurado Jurado \\ Universidad Eafit, Colombia \\ https://orcid.org/0000-0003-1665-0553 \\ jjurado@eafit.edu.co
}

Rodrigo de J. García Estrada Universidad de Antioquia, Colombia https://orcid.org/0000-00 02-7554-7006

rodrigo.garcia@udea.edu.co

\section{RESUMEN}

A partir de la historiografía más destacada, este artículo revisa la historia económica de la región antioqueña durante el periodo 1760-1810, mostrando los cambios más significativos de las estructuras y, en particular, de las relaciones dinámicas entre los diferentes sectores económicos. Teniendo presente la diferenciación y especialización de las distintas regiones neogranadinas, se evidencian las particularidades del caso antioqueño, caracterizado por el crecimiento sostenido de la población, el acelerado proceso de mestizaje, la descomposición de la institución esclavista y el predominio de población libre y multiétnica. Este agente económico permite comprender el desarrollo de la minería aurífera en manos de los llamados mazamorreros, cuya capacidad de consumo explica la proliferación de personas dedicadas al comercio, así como la creación de un mercado interno. 
Palabras claves: demografía, historia económica, minería, comercio, agricultura.

Códigos JEL: N9, N46, N76.

\section{ABSTRACT}

Based on the most important historiography, this article reviews the economic history of the region of Antioquia during the period 1760-1810, showing the most significant changes in the structures and, particularly, in the dynamic relations between different economic sectors. Bearing in mind the differentiation and specialization of the different Neogranadine regions, the particularities of the Antioquia case are evident, as shown by the sustained growth of the population, an accelerated process of miscegenation, the decomposition of slavery, and the predominance of a free and multiethnic population. It was precisely this economic agent which allowed to understand the development of gold mining in the hands of the so-called "mazamorreros", whose consumption capacity explains the proliferation of people engaged in trade and, in turn, the creation of an internal market.

Keywords: Demography, economic history, mining, commerce, agriculture.

JEL Codes: N9, N46, N76. 


\section{INTRODUCCIÓN}

Los rasgos económicos, sociales y culturales de la provincia de Antioquia al filo de la independencia se configuraron durante un largo y complejo proceso histórico y fueron la matriz histórica de lo que se ha denominado el ethos regional antioqueño, no obstante las complejas y vertiginosas transformaciones políticas que este periodo supuso para la región y para toda Hispanoamérica. Como toda sociedad de Antiguo Régimen, la antioqueña de finales del siglo XVIII era rural y campesina, basada en diferenciaciones jerárquicas entre castas y linajes, cuyos vínculos se definían a partir de la rígida estratificación socio-racial, de difícil movilidad y escasa posibilidad de ascenso. Todo ello implicaba que el ordenamiento social se definiera a partir del gobierno y dominio de una élite con ínfulas de nobleza, conformada por una minoría de españoles y sus descendientes criollos nacidos en América (considerados blancos). En lo más bajo de la base de la pirámide se localizaba la población indígena y otro porcentaje significativo de esclavos de origen africano. Tal ordenamiento se expresó en la segregación social y espacial entre la "República de los españoles" y la "República de los indios".

Por otro lado, como resultado de un acelerado y avanzado proceso de mestizaje, proliferó durante el siglo XVIII una población libre, sin mayores regulaciones en lo jurídico, y por tanto no existían instituciones para su control, como sí ocurría con los negros esclavos o con las comunidades indígenas. Estos habitantes, conocidos como "libres de todos los colores", eran mestizos, mulatos y zambos, de condiciones socioeconómicas diversas y cuyo modo de vida laxo e informal contradecía el modelo oficial hispano basado en el matrimonio y la familia católica, el trabajo regular disciplinado y la subordinación a las autoridades civiles y religiosas; lo cual le imprimió su sello a la cultura de los centros poblados. Estos grupos humanos implicaron una transgresión al ordenamiento jerárquico de aquella sociedad de castas, pues fueron reacios a vivir "bajo policía y toque de campana", es decir, en villas y poblados, donde pudieran ser controlados por la Iglesia y el juez. En forma paulatina se integraron al ordenamiento social como grupos medios de libres, base de una sociedad nueva de campesinos que representa la matriz histórica de lo que se ha denominado "la antioqueñidad".

El presente texto tiene como objetivos (i) aportar a la conmemoración bicentenaria de la Independencia un texto que brinde elementos para comprender mejor el contexto histórico del proceso político; (ii) ofrecer una sín- 
tesis histórica, por sectores, de los principales cambios y permanencias en las estructuras económicas de la región antioqueña entre finales del siglo XVIII y la primera década del XIX; y (iii) recalcar las particularidades económicas y sociales de Antioquia, señalando las diferencias con respecto a otras provincias neogranadinas.

\section{REFORMAS BORBÓNICAS Y CAMBIOS ECONÓMICOS EN ANTIOQUIA}

Entre 1778 y 1810 se puede delimitar un periodo con rasgos definidos y expresiones particulares en Antioquia. En la metrópoli, el gobierno de Carlos III (1759-1788) adelantó el programa de reformas institucionales y fiscales de los Borbones con la intención de incrementar el comercio colonial, reestructurar la administración virreinal, restringir la influencia criolla en el gobierno y crear mecanismos más eficaces para explotar fiscalmente las colonias (Safford \& Palacios, 2002, pp. 145-159). También hizo parte de estas transformaciones la libertad de comercio -siguiendo el ejemplo de sus rivales Inglaterra y Francia-, la cual le quitó el monopolio a Cádiz en los intercambios comerciales entre la metrópoli y sus reinos ultramarinos con el objetivo de aumentar las exportaciones desde la península, disminuir la salida de metales preciosos que iban a parar a manos de los comerciantes y, por contrapartida, incrementar su flujo hacia el tesoro real (Bohórquez-Barrera, 2009, p. 19). Sobresale en este periodo que la política española hacia la Nueva Granada se formulara por vez primera dentro de una estrategia coherente para controlar las colonias y encauzar su potencial económico y fiscal. En este sentido, solo tardíamente las reformas lograron una mayor coherencia con los propósitos de los Borbones. Todo ello encaminado a establecer una "modernización defensiva" del Imperio Español en un contexto de guerras internacionales que obligaban a fortalecerse fiscal y militarmente. Según el historiador norteamericano John Leddy Phelan, las modificaciones se introdujeron primero en Cuba, pero desde 1763 se puso en marcha el primer intento de modernización defensiva a gran escala en el virreinato de Nueva España a cargo del visitador general José de Gálvez (1765-1771), quien luego de su exitosa experiencia mexicana fue premiado como ministro de Indias de Carlos III (entre 1776 y hasta su muerte en 1787). Desde su alto cargo ministerial, José de Gálvez fue el artífice de la aplicación de las reformas aclimatadas en México a los virreinatos de Nueva Granada y Perú, encargando para ello a 
los visitadores Juan Francisco Gutiérrez de Piñeres y Juan Antonio Areche, respectivamente (Phelan, 1980, p. 21). ${ }^{1}$

La visita general de Piñeres en la Nueva Granada, entre 1778 y 1781, consistió en la aplicación, con pequeñas variaciones, de las directrices de Gálvez en México, consistentes en la creación del monopolio del Tabaco rentable, la administración directa del sistema fiscal por parte de la monarquía, la expulsión de los criollos de cargos públicos, y restricciones al poder del virrey (Phelan, 1980, p. 21). Dado que las reformas fiscales generaron un profundo malestar político, expresado en revueltas e insurrecciones populares como la de los Comuneros en 1781, junto con constantes sublevaciones de esclavos en Antioquia, se otorgaron mayores atribuciones policivas a las autoridades locales. Estas, dado su imaginario absolutista, su carácter moderno y citadino, pues procedían de centros urbanos de la metrópoli o de ciudades coloniales como Lima o México donde ocuparon previamente otros cargos, vieron como irritantes e intolerables las formas de vida autorreguladas e informales de la población granadina y comprendieron la necesidad de comprometerse de manera más íntima con la vida cotidiana de los vecindarios coloniales como condición para preservar el orden social y llevar a cabo el reformismo.

Antonio Caballero y Góngora, virrey y arzobispo de la Nueva Granada, cuya gestión coincidió con la visita de Piñeres y quien enfrentó la insurrección comunera, consideraba necesario un control más estricto de la plebe, pues era "intrínsecamente alborotador e insolente". Además, estaba convencido de que gran parte de la población vivía en un estado de indolencia y libertinaje, dispersa por los campos y aislada de una disciplina social y religiosa rigurosa. Para el Virrey, los súbditos de estas colonias no tenían fe ni obediencia en Dios ni en el Rey, y su carácter indomable era la causa de todos los males. Para domar a estos "indóciles rústicos" recomendó que se agruparan en pueblos sujetos a las instituciones civiles y religiosas "en tanto que los vagabundos y pordioseros debían ser recogidos y forzados a trabajar (Colmenares, 1989, pp. 408-416).

Es importante aclarar que las políticas borbónicas en el virreinato tuvieron su correlato en la provincia de Antioquia, con gobernadores de un claro perfil ilustrado, a partir de las décadas de 1770/1780. Las autoridades se sintonizaron con las directrices de los virreyes y de la metrópoli al im-

La idea de que las reformas Borbónicas solo lograron plasmarse a partir de los años de 1770 es también la versión del historiador Renán Silva (2002, pp. 16-17). 
plementar cambios en sus gobiernos y nuevas medidas sociales, fiscales y administrativas, lo cual fue iniciado por el gobernador don José Barón de Cháves (1755-1769). Sin embargo, el clímax reformista y su carácter intervencionista en la vida social de los vecindarios fue más notable con las administraciones de Francisco Silvestre (1775-1776; 1782-1785), Cayetano Buelta Lorenzana (1776-1781) y Juan Antonio Mon y Velarde, cuyo periodo de gobierno (1785-1788) se ubica entre los dos ocupados por Silvestre. Queda claro, entonces, que las nuevas instrucciones de gobierno solo tardíamente lograron mayor consistencia y sistematicidad, lo cual de todas maneras no fue garantía para su total éxito.

\section{ASPECTOS DEMOGRÁFICOS}

Si se aprecian las tendencias que sugiere el censo de 1778, Antioquia contaba con 48.604 habitantes, de los cuales más de la mitad $(58,4 \%)$ eran "libres de todos los colores" (28.406), lo que expresa la avanzada figuración de los mestizos y mulatos, a los que se sumaba el incremento de negros libertos arrojados por la crisis de la esclavitud. Según cifras de la época, el 18,3 \% de la población era considerada blanca (8.893), que incluía a los españoles y criollos más destacados, y los indígenas un grupo ínfimo que representaba el 5,2 \% (2.514), mientras que los esclavos llegaron a 8.791, es decir 18,1 \% (Jaramillo-Uribe, 1968, p. 11). Es de destacar que para el mismo año el Virreinato de la Nueva Granada llegó a 840.000 habitantes, por lo que se puede estimar que los antioqueños representaban cerca del $6 \%$ del total de la población. También es de resaltar los cambios político-administrativos que experimentó la provincia durante el siglo XVIII, puesto que a mediados de este las jurisdicciones de la villa de San Jerónimo de Ayapel y de la ciudad de Guamocó pasaron a la gobernación de Cartagena, mismos que fueron compensados con la anexión de las ciudades de Arma (perteneciente a Popayán) y los valles de Marinilla, dependiente de Mariquita (Lenis-Ballesteros, 2007a, p. 122-123).

Es llamativo que al terminar las guerras de independencia Antioquia no redujese su número de habitantes manteniendo, por el contrario, una tendencia al incremento gradual desde las últimas décadas del siglo XVIII, a pesar de los masivos reclutamientos de negros esclavos y de voluntarios para las campañas militares en la Costa Caribe y el Sur y la emigración de las familias realistas. Considerando los censos realizados a finales del periodo colonial y aquellos posteriores a 1790, se ha estimado que el crecimiento 
osciló entre 2,5 y $3 \%$ anual. En 1788, la población de la Provincia de Antioquia se estimaba en 56.072 habitantes. Veinte años después, en 1808, se había duplicado al sumar 110.662; tendencia que se aprecia entrado el siglo XIX, pues en 1835 la provincia contaba con 158.017 habitantes (López-Toro, 1979, pp. 85-86; Patiño-Millán, 1985, p. 69; Restrepo, 1942).

Las explicaciones al respecto indicarían que en Antioquia los procesos políticos de ruptura con la metrópoli no fueron tan radicalizados, ni las guerras tan cruentas y devastadoras, debido a que al finalizar la época colonial la provincia era una de las más atrasadas y abandonadas del virreinato, un territorio marginal rodeado de grandes extensiones de frontera y poco integrada al orbe imperial, si se la compara con los centros de poder neogranadinos, como Cartagena -puerto estratégico en el Caribe para el comercio de esclavos, la defensa y la exportación de metales preciosos-, Santafé capital del Nuevo Reino y sede virreinal-, y Popayán -emblema del poder hacendario esclavista en el sur-. Así las cosas, los ejes de dominación colonial no pasaban por la provincia de Antioquia, pues allí no existían ciudades importantes, ni grandes haciendas, ni burocracia considerable, milicias u obispados, tampoco universidades o seminarios, de modo que las guerras no mostraron toda la crudeza que expresó en las ciudades mencionadas (Chaurra-Gómez \& Gutiérrez, 2016).

Es importante indicar que para la época de la independencia se estaba consolidando un poblamiento más equilibrado entre los diferentes centros urbanos, debido a que la crisis de la minería de veta y la creciente presión demográfica sobre las tierras poco fértiles y erosionadas de la ciudad de Antioquia hacia el siglo XVII desataron un flujo de personas que buscaba instalarse en tierras de mayor vocación agrícola en los valles de Rionegro (oriente), Medellín (centro) y Santa Rosa de Osos (norte), para garantizar el abastecimiento de las nuevas explotaciones mineras. Estos nuevos polos de atracción demográfica se caracterizan por tener condiciones más saludables para la vida humana gracias a sus climas fríos y templados, la abundancia de aguas y suelos más ricos para la agricultura y la cría y ceba de ganados, además de mayor actividad minera.

En las postrimerías del siglo XVIII y los primeros años del XIX, el proceso de colonización iniciado desde los tres centros urbanos mencionados definió la configuración geográfica de los poblamientos y su redistribución interregional. Descendiendo en el análisis demográfico y sin considerar las variaciones étnicas en cada localidad, se encuentra que en 1808 , ad portas 
del inicio del periodo independentista, la población de Antioquia llegó a 110.662 habitantes, distribuidos de la siguiente manera: (i) en la ciudad de Antioquia, capital provincial, que incluía para efectos administrativos la zona de los Osos, residía la mayor parte de la población, 45.906 personas (41,5 \% del total); (iii) en la Villa de Medellín y su jurisdicción vivían 30.982 personas ( $28 \%$ del total de la provincia); (iii) Rionegro y Marinilla albergaban 31.723 habitantes, es decir un porcentaje de 28,7 \%; (iv) Zaragoza, al nordeste, tradicionalmente menos poblada, contaba con 2.051 habitantes, correspondientes a 1,9\% del total (Restrepo, 1942). ${ }^{2}$

Lo anterior expresa la forma como el centro de gravedad demográfico de la provincia se desplazaba desde el centro capitalino tradicional -al occidente- hacia el centro-oriente, donde se localizaban los centros urbanos agrícolas y mercantiles en ascenso (Rionegro y Marinilla), que se beneficiaban de su localización en el corredor de caminos cercanos al puerto de Nare, sobre el Río Magdalena. La coyuntura de Independencia manifestó el considerable protagonismo de los comerciantes de las ciudades centrorientales, quienes disputaron el poder político con la élite de la Ciudad de Antioquia, modificando los equilibrios de poder y logrando que sus cabildos fueran reconocidos con cuotas de representación en las Juntas Provinciales formadas durante la Primera República. De igual modo, el protagonismo y la creciente hegemonía regional de la elite de Medellín fue evidente en los diversos momentos en que esta población fungió como capital provisional de la provincia y sede de operaciones de las Juntas Provinciales, hasta que en 1826 se convirtió, de forma irreversible y hasta el momento presente, en capital de la provincia.

\section{ÉLITES REGIONALES Y PODER ECONÓMICO}

Como han señalado María Teresa Uribe y Jesús María Álvarez, la sociedad antioqueña de la época colonial tardía, en particular sus élites regionales, se organizó alrededor de "estructuras parentales" que tenían por base las relaciones familiares como "redes de poder" que integraban a los sujetos por medio de alianzas en torno a los matrimonios o las sociedades mineras y comerciales. Tales filiaciones de pertenencia fueron "integrativas", es decir, fungieron como paradigma del orden social y estatal, extendidas más allá de la familia y hacia grupos sociales amplios, medios y bajos, con la finalidad de lograr consensos, legitimidad, reconocimiento y la reproducción y dirección

2 Con cifras ligeramente distintas, Botero-Guerra (1888, pp. 110-111); López-Toro (1979, pp. 85-86). 
del mismo sistema social y económico. Las redes de poder parental fueron fundamentales en la conformación de las élites locales cuyo poder y cohesión se dirigió al control de recursos económicos, los cargos de dirección política y administrativa y la modelación de los sentidos de la vida desde las instituciones sociales y culturales como la educación, la religiosidad y diversas formas de sociabilidad (Uribe \& Álvarez, 1998, pp. 187-191).

A finales del siglo XVIII, la élite de la provincia de Antioquia, conformada básicamente por blancos, logró consolidar una indiscutible hegemonía regional a partir de alianzas matrimoniales, y políticas que resguardaban el patrimonio familiar y ampliaban y perpetuaban su influencia local desde los cabildos, así mismo este grupo fundó su poder y prestigio en las actividades mercantiles ligadas al rescate del oro, actividad a la que se subsumían la agricultura y la minería. En la cúpula de la estratificación social colonial que constituye la élite blanca se han podido identificar unas veinte familias de criollos y españoles, cuya inmigración se reactivó al filo de la independencia por las oportunidades emergentes en el comercio y la minería. Por medio de alianzas matrimoniales, estas familias rápidamente se integraron a los troncos parentales de criollos, entre cuyos apellidos sobresalían: Álvarez, Uribe, Londoño, Posada, Villegas, González, Gutiérrez de Lara, Piedrahita Saavedra y Arango (Uribe \& Álvarez, 1998, pp. 211-212). De esta manera, los recién llegados de la metrópoli desarrollaron estrechas solidaridades con los intereses familiares y locales, lo que fue fundamental para definir su adscripción a uno u otro bando, realista o independentista, y evitar el radicalismo de las posturas que se presentaron en otras de las ciudades y regiones indicadas.

En la provincia de Antioquia los sectores de mestizos y mulatos no tuvieron formalmente acceso al ejercicio del poder en los cabildos y muy pocos fueron cooptados por las familias blancas mediante alianzas matrimoniales. Sin embargo, la ilegitimidad y su condición étnica no fueron obstáculo para que pudieran acceder a la riqueza y al poder económico, lo que señala la movilidad social que existió para estos sectores medios de la sociedad a través del extendido ejercicio de la minería, la arriería y el comercio. Estas actividades fueron tan promisorias que la condición étnica podía quedar neutralizada por la riqueza como elemento de ascenso social y económico, de modo que algunos mestizos y mulatos pudieron comprar Cédulas de Gracias al Sacar y "blanquearse", lo cual expresa que al filo de la independencia las talanqueras de estratificación social de aquella sociedad de antiguo régimen estaban en descomposición. No obstante, la segregación 
social funcionaba como en cualquier otra provincia mediante la preservación del poder y los criterios de blancura y pertenencia parental como mecanismos de exclusión de sectores plebeyos, además de la concentración de los recursos locales (Uribe \& Álvarez, 1998, pp. 224-232).

\section{PRODUCCIÓN MINERA, MANO DE OBRA Y AMPLIACIÓN DE LA FRONTERA}

Según las investigaciones de Vicente Restrepo, la minería de veta virtualmente desapareció en Antioquia hacia el siglo XVIII y predominaron las minas de aluvión o explotaciones de "oro corrido" en numerosos ríos y quebradas a los que tenían libre acceso una numerosa población de mineros independientes y mazamorreros (Restrepo, 1979; Villegas, 1984). La producción minera se recuperó considerablemente tan solo después de la década de 1750, pues tuvo lugar una más extensiva explotación de los aluviones por una creciente mano de obra libre que subsistía de ellos sin requerir capitales ni herramientas compleja. Así mismo, los mineros se beneficiaron de mejores condiciones para el suministro de víveres a las cuadrillas gracias al avance de los cultivos en las tierras del oriente y centro de la provincia.

Heraclio Bonilla calculó que a comienzos del siglo XVIII la producción de oro en la Nueva Granada fluctuaba en torno al medio millón de pesos anuales, ascendiendo a 650.000 millones a mediados de este siglo y cerrando el mismo con una cifra de dos millones de pesos anuales gracias a que el metal producido en las provincias esclavistas de Chocó y Popayán fue complementado con el de los mazamorreros antioqueños, cuyo aporte se estima en $30 \%$ del total (Bonilla, 2008, p. 452). Vicente Restrepo, luego de contrastar y criticar las cifras aportadas por el barón Alexander Humboldt, José Manuel Restrepo y el profesor alemán Soetbeer, calculó de nuevo la explotación aurífera total y anual para el periodo de estudio (tabla 1).

Tabla 1.

Producción aurífera en Nueva Granada, 1761-1810

Fuente: autores a partir de Restrepo (1979, p. 170)

\begin{tabular}{|c|c|c|c|}
\hline Periodo & Nro. años & Total & Producción anual \\
\hline $1761-1780$ & 20 & 55.800 .000 & 2.790 .000 \\
\hline $1781-1800$ & 20 & 62.775 .000 & 3.138 .75 \\
\hline $1801-1810$ & 10 & 34.875 .000 & 3.487 .500 \\
\hline Total & $\mathbf{5 0}$ & $\mathbf{1 5 3 . 4 5 0 . 0 0 0}$ & $\mathbf{3 . 0 6 9 . 0 0 0}$ \\
\hline
\end{tabular}

Como puede verse, las cifras de los investigadores no coinciden, esto se debe a que las estadísticas no son del todo confiables ya que derivan 
de cifras del quinto real, es decir, corresponden al oro registrado ante las distintas cajas reales. Por fuera de este indicador queda el oro que salía por contrabando y el que no registraban los mineros y comerciantes, cuyo porcentaje es difícil de estimar. Quizás un promedio entre las cifras de Bonilla y Restrepo puede ser cercano a la realidad, aunque es mejor reconocer que los datos son aproximativos y sirven de indicadores, por lo que no son precisos. Salomón Kalmanovitz coincide con Bonilla y plantea que la producción anual de oro era de dos millones anuales a fines del siglo XVIII y comienzos del XIX. Al momento de calcular el PIB de la Nueva Granada en 1800, este mismo autor le atribuye a la minería un porcentaje de $11,6 \%$, muy superior al sector artesanal $(13,6 \%)$ y la agricultura $(54,4 \%)$, sobre un total de 25.751.000 de pesos (Kalmanovitz, 2017, p. 295). No obstante, el investigador Fabio Zambrano, partiendo de los datos de Aníbal Galindo, plantea que la producción agrícola en los quinquenios 1790-1794 y 1801-1805 fluctuó entre 2,4 y 3,7 millones de pesos, respectivamente (Zambrano-Pantoja, 2015, p. 41).

La monografía de la historiadora Lucelly Villegas ha permitido conocer con lujo de detalles el papel de los trabajadores independientes, o mazamorreros, en el desarrollo del renglón minero en Antioquia durante el siglo XVIII, cuya actividad coexistía con la realizada por mineros de cuadrilla, aunque la tecnología y la labor realizada por ambos tipos de productores era casi la misma: recorrer los ríos y quebradas, con batea, almocafre, barretón y "cacho"3 para extraer el oro en polvo depositado en los aluviones (Poveda-Ramos, 1982, p. 43). Al respecto, la historiografía está de acuerdo en que sobre los hombros de estos mineros independientes recayó el peso de la economía provincial, en especial a partir de las últimas décadas del siglo XVIII. ${ }^{4}$ Villegas demuestra que más del $50 \%$ de estos mazamorreros fueron mulatos y que para su actividad utilizaron la mano de obra familiar, esclavos y peones libres, además de complementar la minería con la agricultura de pancoger y la cría de vacas y cerdos con el fin de reducir costos de mano de obra. Así mismo, estos hicieron parte activa de los procesos de colonización "en su afán de buscar minas de oro y obtener alguna parcela de tierra" (Villegas, 1984, p. 110-117).

3 Instrumento de madera o hierro, formado por dos partes cóncavas, usado para el traslado de gravas y arenas.

4 Según José Manuel Restrepo, en 1805 cerca del 85 \% de la producción de oro en Antioquia era producido por los mazamorreros. Citado en: Poveda-Ramos (1982, p. 46). 
Según Villegas, para 1789 habitaban en Antioquia 28.406 libres, entre los cuales los mulatos eran la mayoría, puesto que representaban la cuarta parte del total de población. Este autor además pudo establecer que más de la mitad de los mazamorreros eran mulatos, mientras que los mestizos eran el segundo grupo étnico en importancia, con una proporción entre 20 y $30 \%$ del total de la población. Para el periodo 1770-1795, esta historiadora estudió una muestra representativa de 538 familias de mazamorreros distribuidas en poblados del oriente, norte y centro-occidente (Villegas, 1984, pp. 136/190). Por su parte, en 1778 los esclavos existentes en Antioquia representaban el 18,1 \% (8.791) de la población total. Treinta años más tarde, en 1808 , su proporción se redujo a la mitad $(9,1 \%)$, aunque su número aumentó a 10.045 personas. En adelante, la tendencia fue hacia una gradual disminución de los esclavos, hasta la supresión definitiva de esta institución en 1851 (Botero-Guerra, 1888, pp. 109/114/115). ${ }^{5}$

Aunque algunas de las reformas implementadas por los gobernantes borbones, como el fomento de la agricultura, parecieron disminuir los costos del sostenimiento de los negros esclavos en las minas, hacia finales del siglo XVIII y para el siglo XIX la compra e importación de negros resultaba sumamente onerosa para los empresarios. Además, la manumisión constante de esclavos contribuyó a mermar la participación de la esclavitud en la economía provincial, generando una masa de libertos integrados como "hombres libres" a la economía y la sociedad. De tal forma, es evidente que la debilidad de la esclavitud en Antioquia implicó la extensión social del trabajo minero a una capa considerable de libres, ampliando con ello el mercado provincial, ya que se trataba de una población que trabajaba para obtener su sustento diario y disponía de recursos pecuniarios para comprar lo que no podía producir por sí misma (Jaramillo-Uribe, 1968, p. 87).

Para sacar del atraso a la minería de veta por la falta de conocimientos, técnicas y tecnología, en 1783, el Gobernador Francisco Silvestre, aconsejado por el naturalista José Celestino Mutis, contrató en la capital neogranadina los servicios del relojero francés Louis Laneret con el fin de instalar una fábrica de molinos o ingenios para moler metales, ensayarlos y beneficiarlos por fundición o azogue. ${ }^{6}$ Al parecer, este francés se hizo pasar por alguien experto en mineralogía y maquinaria, además de "habilísimo maquinista", (Lenis-Ballesteros, 2007b, p. 135), pero los resultados de su presencia en la

Cifras similares fueron reportadas por Brew (1977, p. 12).

"Sobre el nombramiento de director de minas de aquella provincia a favor de Don Luis Laneret", (1783-1784), AGN, Colonia, Minas, Leg. 1, Doc. 4, f. 237 r. 
minería antioqueña permiten dudar de su idoneidad. Laneret fue enviado a reconocer unas vetas de oro en el camino de Sonsón, en la cordillera entre Rionegro y Mariquita, reactivó la explotación en Buriticá y empezó a beneficiar minerales en el Espinal y el río Nus. No obstante, las inversiones se perdieron y las minas fueron abandonadas ante la escasa producción que dieron, a lo cual debe agregarse la temprana muerte del francés. ${ }^{7}$ Por ello, la mayoría de la producción aurífera de esta provincia siguió descansando en las laboriosas manos de los mazamorreros. ${ }^{8}$ Es destacable que, según las cifras aportadas por Jorge Orlando Melo, la productividad minera en Antioquia es ascendente en la segunda mitad del siglo XVIII y al finalizar esta centuria llegó a 3.662.000 pesos, superando al Chocó, que sumó 2.581.000, y al Cauca, con 3.324.000 pesos (Urrutia-Montoya \& Ortiz-Riomalo, 2015, p. 153).

La historiadora Beatriz Patiño ha señalado las categorías bajo las cuales los trabajadores se sujetaron a los medianos y grandes propietarios, lo que expresa en parte sus relaciones de subordinación a las elites locales ( $\mathrm{Pa}$ tiño-Millán, 1988, p. 78). Esta autora demuestra cómo la posesión de una parcela o el ejercicio de la minería les permitió a los campesinos obtener márgenes de independencia económica, aunque también era frecuente complementar los ingresos mediante contratos con quienes necesitaban mano de obra, casi siempre propietarios de tierra en mejores condiciones. "Vivir en tierras ajenas", "estar agregado para mantenerse", "vivir a merced" o "en tierras arrendadas", suponían condiciones de trabajo y relaciones laborales definidas bajo las cuales se tenía derecho a cultivar una chacra, criar animales y construir una vivienda a cambio de trabajo o dinero. Las relaciones de dependencia bajo estas modalidades de contratación se pueden catalogar como "libres", pues no parecieron cohibir la independencia y movilidad de los trabajadores. El peonaje libre tuvo un importante protagonismo entre estas formas de trabajo, suponiendo mayores grados de autonomía y libertad para los labradores, quienes vendían por un salario su capacidad laboral. Adicionalmente, y de acuerdo con lo sugerido por Roger Brew, dado que existía un exceso de mano de obra en las regiones del centro de Antio-

7 "Certificación del Cabildo de Santiago de Arma sobre la conducta del Sr. Gobernador Francisco Silvestre", 17 de septiembre de 1785. Archivo Casa de la Convención de Rionegro (ACCR), Varios, Tomo 10, f. 87.

8 Es del caso mencionar que en 1756 hubo intentos por explotar las vetas de Buriticá, primero por el minero Antonio Ferreiro Cervino, luego por los padres de la Compañía de Jesús, quienes fracasaron debido a la persistencia en técnicas antiguas. Después, en 1767, el gobernador José Barón de Chaves trató de motivar a los antioqueños para que aprovecharan estas minas, pero no tuvo eco. En 1776, el gobernador Francisco Silvestre conformó una compañía con un grupo de comerciantes y mineros de Medellín, pero ocho años después tuvo que reconocer que el intento fue un fracaso (Patiño-Millán, 2011, p. 191-192). 
quia y los salarios eran muy bajos, los terratenientes no tenían necesidad de establecer términos especiales de arrendamiento de tierra o de contrato de trabajo con el fin de conseguir mano de obra. De hecho, los salarios eran bajos y las rentas altas. Además, el carácter de la élite que controlaba el poder político hacía que estuviera interesada en promover la movilidad de los trabajadores y con ello la fundación de pueblos allende la frontera agrícola, con la finalidad de convertir a trabajadores pobres, vagabundos y desocupados en prósperos colonos y lograr la consiguiente apertura de nuevos caminos y centros urbanos para su comercio (Brew, 1977, p. 30).

Es necesario destacar que hacia el filo de la independencia el predominio de formas de contratación flexibles de la mano de obra en el campo también estuvo muy ligado a la temprana y acentuada crisis de la esclavitud (Álvarez, 1988, p. 64). En la jurisdicción de la ciudad de Antioquia, donde se localizaron los más tradicionales distritos mineros que jalonaron la colonización temprana de la provincia hacia el siglo XVI, se asistía durante el siglo XVIII a una especie de transición de la mano de obra esclava a la libre. Según Patiño, este proceso se explica por la crisis minera que obligó a muchos propietarios de la región a trasladar parte de las cuadrillas de esclavos a sus haciendas, buscando mediante la diversificación de actividades sortear las dificultades del momento. Esto explica, entonces, la combinación de esclavos y mano de obra libre en las grandes y hasta medianas propiedades, así como la transición del primero hacia el segundo, hecho que fue más evidente en la jurisdicción de la ciudad de Antioquia, pero de igual forma en los territorios administrados desde Rionegro, Marinilla y Medellín (Patiño, 1985, pp. 62-63). Este proceso estuvo bastante ligado a la manumisión de los mismos esclavos, quienes fueron conducidos por sus propios amos a convertirse en sus "agregados", "mercedarios" o "arrendatarios" a cambio de concederles la libertad. El masivo acceso de los esclavos a la condición de libres se logró mediante una gracia de los dueños en vida por medio de testamentos o la compra que hicieran de ella los esclavos, práctica bastante común, pues los amos les concedieron el permiso para trabajar para sí uno o dos días de la semana, lo cual facilitó su acceso a formas primigenias de ahorro y capital, permitiéndoles transar con otros como si fueran agentes económicos libres (Patiño, 1985, p. 77). Todo ello sugiere patrones de ocupación de gran flexibilidad e irregularidad en las estructuras agrarias y, por ende, de los mecanismos de control social sobre la población libre. 
Teniendo en cuenta la anterior, se evidencia que la flexibilidad de las formas de contratación en el campo a comienzos del siglo XIX propició la formación de grupos de trabajadores independientes con niveles de vida precarios y hábitos laborales móviles e irregulares, que a pesar de sus amplios grados de autonomía fueron una importante cantera de población disponible y partícipe de los proyectos político económicos liderados por las élites de la Independencia. El acceso a tierra por parte de mestizos, mulatos y blancos tuvo lugar a pesar de un férreo acaparamiento de terrenos derivado de la concesión de mercedes de tierra y gracias reales otorgadas por la Corona, que con el tiempo sufrieron un paulatino proceso de subdivisión, dando lugar a pequeñas y medianas propiedades. Entre las causas de tal subdivisión de los latifundios estuvo las crisis de la minería de veta en los distritos mineros circunvecinos a Santa Fe de Antioquia hacia mediados del siglo XVII (Álvarez, 1988, p. 55; Patiño, 1985, p. 78).

La apertura continua de la frontera agrícola y minera fue una variable de este proceso que llegó a una nueva etapa en las últimas décadas del siglo XVIII y primeras del XIX, cuando el crecimiento demográfico aceleró, mientras que la disponibilidad de tierras para capas medias de mestizos y mulatos no crecía al mismo ritmo (Patiño, 1988, p. 78). A partir de allí, se fue desarrollando un considerable conjunto de pequeñas y medianas propiedades que resultaron insuficientes para mantener a sus propietarios, familiares y descendientes y una creciente masa de vagos, trabajadores y pobres, cuya presencia en centros poblados de Antioquia, Medellín y Rionegro elevó la alarma social en la época (Jurado, 2004).

\section{LA AGRICULTURA Y LOS PROCESOS DE COLONIZACIÓN}

La historiografía de la región ha destacado que en Antioquia proliferaron pequeñas y medianas propiedades que coexistían con estancias y haciendas, con lo cual moderaron el poder de grandes propietarios que no fueron los típicos hacendados y señores de las tierras andinas (Brew, 1977, pp. 3-4). Aun para la subregión occidental de la provincia, en la jurisdicción de la ciudad de Santa Fe de Antioquia, donde había una clase propietaria de grandes extensiones con rasgos tradicionales similares a los de la sociedad caucana o cartagenera, la formación de latifundios no supuso un carácter marcadamente nobiliario, como sucedió en los Andes Centrales de América del sur (Patiño, 1985, p. 83). 
En diferentes estudios se ha encontrado que los rasgos modernos de la élite empresarial antioqueña pueden derivarse del hecho de que la minería y el comercio, actividades de gran importancia social en la región, socavaran las bases de la hacienda e impidieran el desarrollo de industrias artesanales al absorber gran parte de los recursos económicos y de la mano de obra, por lo cual los patrones de ocupación se dirigieron hacia labores menos nobiliarias (López-Toro, 1979, pp. 31-40; Safford, 1989; Twinam, 1985). Además, instituciones como la mita y la encomienda, que dieron rigidez a la estructura socioeconómica en la zona cundiboyacense, sucumbieron de forma temprana o fueron casi inexistentes en Antioquia debido a la rápida extinción de la mano de obra indígena. Así lo señala Roger Brew al destacar que el atractivo que ejerció la minería explica, en gran parte, que los antioqueños no hayan desarrollado industrias artesanales y domésticas, como sucedió en la región de Santander, donde estas actividades absorbieron las iniciativas de la población agrícola (Brew, 1977, p. 19.).

Para explicar el carácter excepcional de la élite antioqueña no han faltado las explicaciones de tipo geográfico y ecológico, las cuales apuntan a desentrañar la manera en que las condiciones del medio ambiente natural pudieron disponer a los grandes propietarios hacia actividades y actitudes empresariales más modernas. Y es que, al parecer, la escasez de recursos en una difícil y escarpada geografía de tierras pobres para la agricultura propició el desarrollo de actividades económicas menos ligadas a valores nobiliarios. Para el geógrafo norteamericano James J. Parsons, "Los suelos del batolito granítico de Antioquia eran superficiales e improductivos, similares a los de Nueva Inglaterra, sobre laderas escarpadas que desestimularon el afán por acumular bienes raíces, consecuentemente reduciendo la tendencia hacia el latifundio, tan característico de otras regiones latinoamericanas" (Parsons, 1980, p. 6). Así, los grandes propietarios de Antioquia no fincaron en la tierra todos sus intereses, pues tuvieron en la minería y el comercio actividades más lucrativas y "honoríficas", lo que significa que tales élites tendieron a sostener relaciones integrativas y flexibles con la población subordinada, en su mayoría "libres de todos los colores" (Brew, 1977, p. 210). A pesar de que algunas investigaciones han mostrado la preponderancia de la pequeña y mediana propiedad en Antioquia, también se ha encontrado que las tierras más aptas para la agricultura y la ganadería existentes en los valles interandinos y mesetas de clima templado y frío fueron acaparadas por una minoría de españoles y 
criollos, obligando a capas sociales desposeídas a buscar tierras disponibles en zonas de frontera (Patiño, 1988, p. 77).

Esta situación de los pobladores con poca tierra (o sin ella), se aprecia en los testimonios de la época, cuando las autoridades asociaron el problema de la pobreza con la estructura desigual de su tenencia. Don Pedro Rodríguez de Zea, comisionado para el Valle de Aburrá por el Gobernador Francisco Silvestre, afirmaba que la zona estaba muy habitada y estrecha, resultando de ello que el vecindario estaba muy crecido y en su mayoría carecía de los medios necesarios para alimentarse y vestirse debido a la insuficiencia productiva de las pequeñas propiedades. ${ }^{9}$

Testimonios similares relativos a la pobreza de sus pobladores, principalmente las castas, se encuentran para la jurisdicción de la ciudad de Antioquia debido a las restricciones para acceder a la tierra en un ambiente de profundas dificultades económicas, dada la aridez de las tierras cálidas, que resultaban poco propicias para la agricultura, y la estrechez del mercado local en una zona alejada de los principales caminos hacia el río Magdalena, principal vía de comunicación con las demás provincias del virreinato y con el exterior hacia el mar Caribe. Al respecto, el gobernador Cayetano Buelta Lorenzana afirmaba que los pobladores del lugar vivían del cultivo de maíz, fríjol y caña de azúcar, y que el mercado era tan restringido que se ceñía al trueque de artículos ofrecidos por los mercaderes, como cacao y lienzos, cuyos precios eran bastante altos por ser productos importados de otras provincias. Este hecho dificultaba aún más la situación de los labradores, de quienes decía que eran todos muy pobres, desaseados, mal vestidos y descalzos, y cuya alimentación se restringía a maíz con ají. ${ }^{10}$ Como indica este testimonio, el grueso de los habitantes de la zona eran pequeños y pobres agricultores que utilizaban como recurso básico la mano de obra familiar para el autoconsumo y en su mayoría vivía en los ejidos comunales de los centros poblados y en las tierras de los resguardos indígenas de sus respectivas jurisdicciones, debido a que los libres se habían tomado las tierras de una población indígena prácticamente inexistente, ya por su declive demográfico o por su avanzado proceso de hispanización y mestizaje. La situación no era distinta entre los trabajadores del campo y los mazamorreros del Valle de los Osos, ni en la jurisdicción de Rionegro y Marinilla, donde fue noto-

9 A.H.A. Tomo 76, doc. 2104, fols. 109-110. Hay otro testimonio similar para el Valle de Aburrá, A.H.A. Censos. Tomo 343. Doc. 6538, fol. 9r. Para el caso de la región de los Osos, al norte de Antioquia, Robledo, E., 1954, tomo I, pp. 75-76.

10 A.H.A. Comuneros. Tomo 332. Doc. 6328, fols. 28 r y v. 
rio el deterioro económico de los pequeños propietarios y los desposeídos, dispersos en sus inmediaciones rurales, entre quienes predominaban los mestizos, mulatos y negros, aunque no faltaban vecinos blancos (Twinam, 1985, pp. 48-49).

La preocupación de las autoridades por la creciente presencia en los centros urbanos de una población flotante no sujeta a las obligaciones sociales, económicas y fiscales que legalmente le estaba prescrita a los indígenas y esclavos, se percibe desde 1754, cuando la legislación de tierras trató de solucionar aspectos relativos a su posesión (Tovar-Pinzón, 1975, p. 95). Para las autoridades coloniales, el problema de la posesión de la tierra y las situaciones de vagancia y pobreza asociadas a ella llegó a hacerse explícito con el virrey Manuel de Guirior (1773-1775), quien inició la sucesión de virreyes ilustrados que no eran meramente militares destinados a defender al imperio de la amenaza inglesa. Según este funcionario, el sistema de composiciones y de mercedes de tierras había sido concebido originalmente para un medio con pocos pobladores y grandes extensiones disponibles; sistema que ya no se adecuaba a las necesidades de la época, pues había sido diseñado para recolectar recursos fiscales, teniendo como nefasto resultado el monopolio de tierras por parte de terratenientes que obstaculizaban su efectiva explotación y su ingreso al mercado. El virrey proponía que en lugar de seguir otorgando mercedes y tierras realengas en grandes extensiones, se facilitase un acceso moderado a la propiedad a todo quien estuviera dispuesto a cultivarlas (Colmenares, 1989, p. 19). Sin embargo, debido a que no se había transformado la estructura inequitativa de la tenencia de la tierra, se propuso la Real Cédula del 2 de agosto de 1780, la cual facilitó mayores oportunidades para su adjudicación y para promover la fundación de centros poblados como estímulo al comercio con objeto de integrar nuevas tierras a la agricultura y facilitar la conversión de desempleados en trabajadores productivos. ${ }^{11}$ Aunque la legislación conservó el privilegio elitista de poseer grandes propiedades y no se suprimieron los costosos trámites para adjudicarla a los más pobres, la ley estimuló un proceso de apertura de tierras donde la repartición de grandes propiedades creó la expectativa de convertir los pobres en prósperos colonos. Así, se esperaba mejorar el control social sobre los nuevos pobladores al convertirlos en trabajadores sedentarios al alcance de las instituciones civiles y de la Iglesia Católica, con asiento en los centros urbanos.

11 Real Cédula de Tierras del 2 de agosto de 1780. Anuario de Historia Social y de la Cultura. Bogotá, Universidad Nacional de Colombia, número. 10, 1982, pp. 231-244. 
Con la pretensión de descongestionar los poblados, los gobernadores Francisco Silvestre (1782-1785) y Juan Antonio Mon y Velarde (1785-1788) propusieron y gestionaron durante sus administraciones la apertura de colonias agrícolas y la fundación de nuevos poblados en tierras realengas alejadas de los centros urbanos ya establecidos, donde ya no quedaban tierras para distribuir. Roberto Luis Jaramillo bosqueja de manera acertada los flujos de colonización, dirigida y espontánea, que convirtieron en propietarios a pobladores de la siguiente manera: (i) de Santa Fe de Antioquia se avanzó hacia el sur por el río Cauca, poblando los sitios de Titiribí y Anzá, el valle de Urrao, Abriaquí, Cañasgordas y Frontino; (ii) el Valle de los Osos se pobló con familias procedentes del valle de Aburrá y surgieron poblaciones como Yarumal y Carolina del Príncipe; (iii) hacia el suroeste de Medellín se fundaron los pueblos de Amagá y Titiribí y partiendo de estos lugares se desplegó la fundación de numerosos poblados al otro lado del río Cauca; (iv) del valle de San Nicolás y los municipios de Rionegro y Marinilla salieron los pobladores de Sonsón y Abejorral, al sur; (v) la población del oriente en la ruta del Nare se llevó a cabo desde Marinilla y logró pronto asentamientos en El Santuario, El Peñol, San Carlos y Cocorná; (vi) en el Bajo Cauca prosiguió el poblamiento por parte de mazamorreros en distintas direcciones (Jaramillo, 1988, p. 177). Al finalizar el siglo XVIII, la fama recuperada por los minerales de Los Remedios (en el nordeste) atrajo colonos y propició la fundación de sitios, unos hacia el río Magdalena, otros en el río Nechí, en San Lorenzo de Yolombó y en las riberas del Nus (Lenis-Ballesteros, 2007, p. 150). En cada uno de los frentes de colonización mencionados, durante y luego de la independencia, se fundaron nuevas colonias agrícolas y poblados que bajaron la presión social en las ciudades y villas coloniales y propiciaron las condiciones para un nuevo incremento demográfico y el desarrollo del mercado interno.

Se comprende mejor el significado que alcanzaba el problema de la posesión de la tierra y que se lograra su distribución en minifundios si se sabe que el sector agrícola era uno de los cuellos de botella de la economía provincial. Desde antaño, la minería absorbía gran parte de los recursos técnicos y humanos e igualmente el comercio, mientras las labores agrícolas permanecían en un segundo plano. Entre la minería y el comercio de un lado y la agricultura del otro, se estableció un inestable desequilibrio que se tornaba bastante crítico en épocas de sequías y plagas, afectando el suministro de víveres con variaciones en las diversas localidades. Y es que, en 
general, los grandes y medianos propietarios fueron incapaces de producir excedentes de consideración para el comercio local, y sus artículos, por sus altos precios de venta, se destinaban para el consumo y abasto de las cuadrillas de esclavos y de mineros y mazamorreros, principalmente. Así las cosas, la tendencia fue de una preocupante dependencia de la provincia de los víveres y géneros que se importaban de otras provincias del Virreinato de la Nueva Granada y aun de la metrópoli.

De la zona central circunvecina a Santa Fe de Bogotá, denominada el Reino, y del Socorro, al oriente, llegaban a la provincia de Antioquia telas burdas de lana y algodón, ropas, sombreros, junto con alimentos como la harina de trigo y el cacao. Por el puerto de Cartagena ingresaban manufacturas extranjeras, loza, herramientas y artículos de lujo. De la costa Caribe y del interior caucano y llanero, cerca de Venezuela, se transportaban para Antioquia ganados, cebos, mulas, cueros y tabacos, este último uno de los productos más caros procedentes de los valles internos del río Magdalena en Neiva. Provenientes de la Audiencia de Quito se recibía una amplia gama de objetos artísticos, tejidos y manufacturas. El consumo de alimentos que crecía al finalizar el siglo XVIII como consecuencia de un incremento en la población, significó un factor de consideración que expresaba el desequilibrio entre los habitantes de la región y la disponibilidad de tierras para su cultivo en los valles más poblados.

Con sentido realista y la finalidad de resolver las restricciones de la economía de la provincia, el gobernador Juan Antonio Mon y Velarde (17851788) puso de presente la situación marginal de la agricultura y la necesidad de aumentar la producción de víveres: "La agricultura que hasta aquí se ha mirado con poco aprecio debe ser atendida y fomentada, como que es el fundamento de la industria de la minería y del comercio; y por consiguiente, es el principio elemental de toda prosperidad [...]" (Robledo, 1954, pp. 102103). Por ello, el gobernante ordenaba a los agricultores la siembra anual de seis almudes de maíz para afianzar su abundancia y la vinculación de la mano de obra libre, pobre e improductiva a este sector de la economía regional (Brew, 1977, pp. 4-5).

\section{EL COMERCIO AL POR MAYOR Y AL DETAL}

De manera temprana, el economista Luis Ospina Vásquez puso en entredicho la supuesta fragmentación e incomunicación de las distintas provincias neogranadinas y consideraba que quienes calificaban de "pobre" el 
comercio entre estas solo pronunciaban una queja, que como tal debía tomarse. Al respecto, Ospina recalcó que "el intercambio entre las colonias era mayor de lo que generalmente se supone, y gozaba de bastante libertad" (Ospina-Vásquez, 1987, p. 66). Esto lo explica por la especialización regional ("producción manufacturera en ciertas poblaciones de la faja oriental, minería en las regiones occidentales, ganadería en ciertas zonas calientes"12), sosteniendo que con los productos extranjeros no manufacturados era imposible abastecer a la población de los elementos que necesitaba, por lo cual era indispensable suplir el mercado con la producción nacional (Ospina-Vásquez, 1987, p. 60).

Es importante retomar los análisis del economista Álvaro López Toro, quien plantea una síntesis adecuada de la estructura y el funcionamiento de la economía colonial en Antioquia. Según este autor, la peculiaridad de Antioquia reside en la presencia de un actor económico carente de recursos de capital y tierra, una parte considerable de la población económicamente activa, que encontró oportunidades de subsistencia en actividades independientes como la búsqueda de oro en zonas de frontera. Dicho actor son los mazamorreros, cuya producción llegó a representar la mayor parte de la producción de este metal precioso. La influencia de este grupo social indujo a la formación de una "clase mercantil" cuya "doble función consistía en rescatar una producción metálica dispersa y abastecer un mercado no cautivo de consumidores de víveres, vestido y otros géneros" (López-Toro, 1968, p. 352). Debido al crecimiento desigual de los sectores minero y agropecuario se produjo una traslación del poder económico y político hacia la "clase comerciante", proceso que inició a fines del siglo XVIII y que se consolidó luego de la independencia, en forma paralela a los fuertes y constantes procesos de colonización de las fronteras agrícola y minera, todo ello a favor de la ampliación del mercado para los bienes importados por los comerciantes (López-Toro, 1968, pp. 351-359).

Se destaca el crecimiento de los comerciantes en las principales ciudades y villas como uno de los cambios sociales más significativos de fines del periodo colonial. Estos comerciantes, que se especializaron según las dimensiones del mercado que atendían, se pueden subdividir en (i) pulperos o tenderos, cuyos principales consumidores eran los habitantes de los centros urbanos; (ii) rescatantes, es decir, intermediarios entre los agricultores y los mineros, tanto de cuadrilla, como los mazamorreros; (iii) e importadores,

12 Ospina-Vásquez (1987, p. 60). 
quienes se desplazaban con sus arrieros y mulas hasta Cartagena, la región manufacturera de Santander, la capital de la república o la ciudad de Quito para conseguir los productos requeridos para la producción de estancias y minas y para el sustento de los trabajadores y sus familias. Lo inédito del asunto es que a fines del siglo XVIII en las ciudades de Antioquia y Rionegro, en las villas de Medellín y Marinilla -o en otros centros poblados como Zaragoza, Remedios o Santa Rosa de Osos-, surgió el comerciante profesional, es decir una persona cuya actividad fundamental fue la compra y venta de mercancías, que estaba viajando continuamente o tenía personas que lo hacían por ellos y declaraban públicamente ejercer este oficio (Lockhart, 1982, p 101). Entre estos profesionales del comercio había una serie de gradaciones y jerarquías. Así mismo, entre quienes pertenecían a las diferentes escalas de la actividad había relaciones de intercambio, créditos y favores mutuos.

Los estudios de Beatriz Patiño han permitido conocer la trayectoria de un grupo de representativo de mercaderes españoles que durante la segunda mitad del siglo XVIII se establecieron en Antioquia, logrando un lugar destacado por sus considerables importaciones y mostrando un proceso de inserción social y vinculación a las élites de los centros urbanos más importantes. Los personajes estudiados por Patiño son los siguientes: Bernardo Martínez Porrúa, Juan José Callejas, Manuel Santamaría Fernández, José Rodríguez de Paula, Juan Pablo Pérez de Rublas, Francisco Campuzano Fernández, Juan Carrasquilla Monje y Juan Francisco Rodríguez Obeso, procedentes en su mayoría de lugares al norte de la península y de Andalucía. Según Patiño, tras de un inmigrante que lograba asentarse con éxito en un lugar y conseguida cierta fortuna, llegaban familiares y paisanos en busca de la misma suerte $y$, en algunos casos, a insertarse y aportar en la expansión de la red comercial del pionero. El recién llegado se integraba a las redes existentes entre las diferentes localidades de la provincia y sus conexiones con otras ciudades del virreinato. Este nuevo personaje debía ser además muy hábil para darse a conocer de las personas indicadas y hacer parte de causas benéficas e institucionales que podían abrirle el camino a un matrimonio conveniente dentro de las parentelas locales y recursos financieros para sus actividades. Al parecer, los primeros años le servían de aprendizaje al inmigrado, por lo cual se le denominaba "mercader residente", pero al cabo de cinco o más años y de haber contraído matrimonio se le empezaba a considerar como "vecino" (Patiño-Millán, 2006). 
Las redes comerciales eran el resultado de la actividad cotidiana por parte del mayorista para sostener e incrementar sus relaciones con proveedores y clientes. Los importadores antioqueños se surtían de los productos que necesitaban con mayoristas de los grandes centros de distribución de mercancías, a saber: Cádiz, Cartagena, Santafé, Mompox, Honda y Popayán. Su clientela estaba formada por tenderos y consumidores directos que hacían sus pedidos al por mayor y al detal en los poblados donde tenían su tienda. Las relaciones con los proveedores y con los clientes estaban basadas en el buen crédito y la confianza construida día a día, ya que entre quienes hacían parte de estas redes se suministraban mercancías a crédito, se compartían cartas de recomendación, préstamos en dinero, pago de deudas a terceros y todo cuanto contribuyera al buen funcionamiento de los negocios (Patiño-Millán, 2006).

Es importante señalar que el papel de los comerciantes en la economía antioqueña a fines del periodo colonial abarca una serie de aportes en la conformación de un mercado interno al articular los centros urbanos donde residían los poderes públicos (Santa Fe de Antioquia, Medellín, Rionegro, Marinilla), con poblados de mediana importancia (Santa Rosa, San Pedro, San Carlos, Carolina, Yarumal, Amagá, Titiribí, entre otros), y a estos con sus zonas de colonización y áreas de producción agropecuaria, incentivando así el consumo de productos importados entre la población campesina y minera y "rescatando" el oro en polvo producido en su mayoría por mazamorreros, ya que, como afirma la historiadora Ann Twinam, los rescatantes afincados en los distritos mineros "se disputaban el oro en polvo y los compradores" (Twinam, 1985, p. 96). Además de desarrollar el mercado interno, estos comerciantes jugaron un papel importante en el proceso de aplicación de la reforma monetaria instaurada por los funcionarios borbónicos, evitando que el metal precioso estuviera en manos de los consumidores o que saliera por contrabando, fomentando además el uso de las monedas de plata para el intercambio al menudeo, con lo cual la administración pudo controlar y concentrar la mayor parte del oro producido, fundirlo y acuñarlo, para hacer las remesas correspondientes a la Corona española.

Un indicador notorio del auge del comercio a fines del siglo XVIII es que hasta 1763 la Casa de Aduanas de Santa Fe de Antioquia, donde los importadores registraban el ingreso de mercaderías, era la única de toda la provincia. Sin embargo, ese mismo año se abrieron las aduanas de Medellín y Rionegro, en 1791 la de Marinilla y en 1799 la de Santa Rosa. Otro indica- 
dor explícito del auge comercial es el acelerado incremento de las importaciones entre 1773 y 1810, que pasó de un total de 17.744 en el primer año a 181.080 pesos de oro en polvo en el segundo; aunque hubo años que fueron superiores en el monto de lo importado (1787 [253.914], 1792 [224.014] y 1801 [209.139]) (Twinam, p. 98-100).

Como muestra Ann Twinam, el tamaño del circulante en oro en polvo en la provincia se había convertido en un cuello de botella para el desarrollo del comercio al detal, puesto que su valor era muy alto para transacciones de pequeño monto, por ello, fue clave la reforma de Mon y Velarde para acostumbrar a los antioqueños al uso de la moneda de plata, de menor valor, que posibilitaba la compra de pequeñas cantidades de productos. Este cambio permitió el desarrollo de mercados en las plazas de los centros poblados y las pulperías para que sus habitantes se abastecieran de los elementos necesarios para su subsistencia, además de reducir la tendencia inflacionaria en las zonas mineras, donde los tratantes podían darse el lujo de avaluar por debajo el oro en polvo recibido de los mazamorreros, entregando así una menor cantidad de mercancías a cambio del metálico. La habilidad de Mon y Velarde queda a la vista con su medida de crear un nuevo tipo de tratante que cambiaba por monedas de plata el oro en polvo de mineros y mazamorreros, haciendo competencia a los rescatantes (Twinam, 1985, p. 105). Con estas medidas, complementadas con otras que no son del caso mencionar, en la década de 1790 se había generalizado el uso de la plata y los importadores dejaron de recorrer los distritos mineros con sus mercancías, iniciando el envío de estas a las poblaciones y entregándolas, a crédito, a los tenderos. Los más beneficiados fueron los importadores, puesto que ahora llevaban el oro en barras para sus compras en las ciudades donde se abastecían de sus géneros y traían monedas de plata que entregaban a los rescatantes de plata. A cambio, los importadores recibían oro en polvo, con lo cual suplantaron a la Casa de Moneda de la capital virreinal en su función de abastecer de dinero a la provincia (Twinam, p.110).

Las cifras globales del movimiento comercial en Antioquia dan cuenta del desarrollo inusitado de esta actividad y la forma como esta incidía en las relaciones de poder entre sus principales ciudades, así como las repercusiones políticas de este fenómeno durante la independencia. Según las cifras de Twinam, entre 1763 y 1810 los comerciantes de la capital -la ciudad de Antioquia- importaron un total de 752.791 pesos en mercancías, mientras que en Medellín y Rionegro sumaron 1.431.429 y 2.434.233, 
respectivamente (Twinam, 1985, p.127). Lo anterior revela el rezago de la capital provincial en la producción de metales preciosos y la escasa acumulación de oro en polvo en manos de sus comerciantes, hecho que repercutió en la capacidad de consumo de sus familias. Mientras que las ciudades donde predominaba la población mestiza y mulata, es decir, el centro-oriente de la provincia, fueron el lugar de asiento y desarrollo de actividades de un sector comercial floreciente.

\section{CONCLUSIÓN}

Durante la segunda mitad del siglo XVIII, la provincia de Antioquia experimentó una serie de transformaciones económicas y sociales que rompieron con las estratificaciones de antiguo régimen y fracturaron los valores y las formas de relacionarse con las instituciones coloniales y modificaron las relaciones sociales e interétnicas. Este cambio en la estructura económica, caracterizada por su movilidad y estrechos vínculos entre los diferentes sectores económicos - cuyas riquezas posibilitaron la acumulación originaria de capital en manos de los comerciantes-, permite entender mejor las transformaciones políticas vividas por los antioqueños después de 1810, es decir, la participación de sectores populares en los cabildos abiertos y en la formación de grupos de milicias y en los ejércitos, así como la rápida incorporación de los valores republicanos.

Después de la independencia, como hecho político y militar, las clases dirigentes lideraron la ardua tarea aún vigente de formar un Estado moderno, auspiciar la democracia electoral, promover el crecimiento económico, la integración nacional entre las regiones colombianas, generar la identificación política entre las personas y el Estado, es decir, la ciudadanía, así como promover la cultura y la ciencia moderna por medio de la educación de amplios sectores de la población, que en Colombia se caracteriza por ser fundamentalmente mestiza. La participación de esta población dentro del proceso de independencia presentó importantes diferencias respecto de las élites españolas y criollas, las comunidades indígenas, los negros esclavos o la plebe colonial. 


\section{REFERENCIAS}

Álvarez, V. (1988). La sociedad colonial, 1580-1720. En J. O. Melo (ed.). Historia de Antioquia (pp. 53-67). Medellín: Suramericana.

Bohórquez-Barrera, J. (2009). Más para entretener la miseria que despertar la codicia: los frutos del comercio y los mercados imperiales durante el nacimiento del liberalismo. Nueva Granada (1780-1810). Anuario Colombiano de Historia Social y de la Cultura, 36(1), 17-53.

Bonilla, H. (2008). María Mercedes Botero. La ruta del oro. Una economía exportadora: Antioquia 1850-1890. Anuario Colombiano de Historia Social y de la Cultura, 35, 452-455.

Botero-Guerra, C. (1888). Anuario Estadístico. Ensayo de Estadística General del Departamento de Antioquia. Medellín: Imprenta Departamental de Antioquia

Brew, R. (1977). El desarrollo económico de Antioquia desde la Independencia hasta 1920. Bogotá: Banco de la República.

Colmenares, G. (1989). Relaciones e informas de los gobernantes de la Nueva Granada. Bogotá: Banco Popular.

Chaurra-Gómez, E., \& Gutiérrez, C. (2016). Restablecimiento del gobierno español en la provincia de Antioquia 1816-1819. En R. J. García-Estrada \& Córdoba-Restrepo, J. F. (comp.) El terror y la sangre sublime (pp. 135144). Bogotá: Universidad del Rosario.

Jaramillo, R. (1988). La colonización. En J. O. Melo (ed.). Historia de Antioquia (pp. 177-208. Medellín: Suramericana.

Jaramillo-Uribe, J. (1968) Ensayos sobre historia social colombiana. Bogotá: Universidad Nacional de Colombia.

Jurado, J. C. (2004). Vagos, pobres y mendigos. Contribución a la historia social colombiana, 1750-1850. Medellín: La Carreta.

Kalmanovitz, S. (2017). El PIB de la Nueva Granada en 1800: auge colonial, estancamiento republicano. En S. Kalmanovitz (ed.). Obra selecta (pp. 187-318). Bogotá: Editorial Utadeo.

Lenis-Ballesteros, C. (2007a). Reales de minas y rancherías dispersas: el poblamiento en los distritos mineros de la provincia de Antioquia, siglo XVIII. En A. C. Reyes \& J. D. Montoya (eds.). Poblamiento y movilidad social en la historia de Colombia siglos XVI-XX (pp. 121-151). Medellín: Universidad Nacional de Colombia. 
Lenis-Ballesteros, C. (2007b) Una tierra de oro. Minería y sociedad en el nordeste de Antioquia. Medellín: IDEA.

Lockhart, J. (1982) El Mundo Hispano peruano 1532-1560. Ciudad de México: Fondo de Cultura Económica.

López-Toro, Á. (1979). Migración y cambio social Antioquia durante el siglo XIX. Medellín: Hombre Nuevo.

Ospina-Vásquez, L. (1987). Industria y protección en Colombia 1810-1930. Medellín: FAES.

Parsons, J. (1980). La geografía entendida como exploración y descubrimiento. Lecturas Geográficas, 1, 6.

Patiño-Millán, B. (2006). Comerciantes españoles en Antioquia. Familia y redes de negocios. En Memorias XIII Congreso Colombiano de Historia. Bucaramanga, Universidad Industrial de Santander.

Patiño-Millán, B. (2011). Riqueza, pobreza y diferenciación social en Antioquia. Medellín: Universidad de Antioquia.

Patiño-Millán, B. (1985). Clases sociales y razas en Antioquia durante el siglo XVIII. Riqueza, pobreza y diferenciación social en la Antioquia del siglo XVIII. Medellín: Universidad de Antioquia, Facultad de Ciencias Humanas, Centro de Investigaciones.

Patiño-Millán, B. (1988). La provincia de Antioquia en el siglo XVIII. En J. O. Melo (ed.). Historia de Antioquia (pp. 69-90). Medellín: Suramericana.

Phelan, J. L. (1980). El pueblo y el Rey. La Revolución Comunera en Colombia, 1781. Bogotá: Universidad del Rosario.

Poveda-Ramos, G. (1982). Minas y mineros de Antioquia. Memorias del Simposio Los Estudios Regionales en Colombia: el caso de Antioquia. MedeIlín: Fundación Antioqueña para los Estudios Sociales.

Restrepo, J. M. (1942). Ensayo sobre la geografía, producciones, industria y población de la provincia de Antioquia en el Nuevo Reino de Granada. Semanario del Nuevo Reino de Granada. Bogotá: Biblioteca Popular de Cultura Colombiana, tomo 1.

Restrepo, V. (1979). Estudio sobre las minas de oro y plata en Colombia. MedeIlín: Fundación Antioqueña para los Estudios Sociales.

Robledo, E. (1954). Bosquejo biográfico del señor Oidor Juan Antonio Mon y Velarde, Visitador de Antioquia 1785-1788. Bogotá: Banco de la República. 
Safford, F. (1989). El ideal de lo práctico: el desafío de formar una élite técnica y empresarial en Colombia, Bogotá: Universidad Nacional de Colombia.

Safford, F., \& Palacios, M. (2002). Colombia. País fragmentado, sociedad dividida. Su historia. Bogotá: Norma.

Silva, R. (2002) Los ilustrados de Nueva Granada. 1760-1808. Genealogía de una comunidad de interpretación. Medellín: EAFIT.

Tovar-Pinzón, H. (1975). Algunos aspectos de la sociedad rural en Colombia (Siglos XVIII y XIX). Historia Económica de Colombia. Un debate en marcha. Bogotá: Instituto de Estudios Colombianos y Banco Popular.

Twinam, A. (1985). Mineros, comerciantes y labradores: Las raíces del espíritu empresarial de Antioquia. 1763-1810. Medellín: FAES.

Uribe, M. T., \& Álvarez, J. M. (1998) Raíces del poder regional: el caso antioqueño. Medellín: Universidad de Antioquia.

Urrutia-Montoya, M., \& Ortiz-Riomalo, J. F. (2015). El oro en la Nueva Granada del siglo XVIII: auge minero y desarrollo regional. En A. Meisel-Roca \& M. T. Ramírez (eds.). La economía colonial de la Nueva Granada (pp. 147-199). Bogotá: FCE y Banco de la República.

Villegas, L. (1984). Minería y trabajo independiente en Antioquia colonial. Los mazamorreros. 1770-1820 (trabajo de grado). Medellín: Universidad de Antioquia, Departamento de Historia.

Zambrano-Pantoja, F. (2015) Alimentos para la ciudad. Historia de la agricultura colombiana. Bogotá: Universidad Nacional de Colombia. 